\title{
Severity of obstructive sleep apnoea/ hypopnoea syndrome and subsequent waking EEG spectral power
}

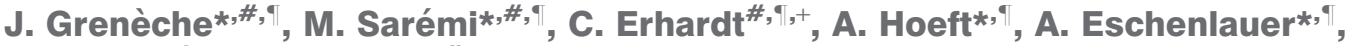 \\ A. Muzet ${ }^{\oplus, \S}$ and P. Tassi*,\#,
}

ABSTRACT: It is well known that most patients with obstructive sleep apnoea/hypopnoea syndrome (OSAHS) suffer sleepiness, although the underlying mechanisms of this relationship remain unclear. The present study examined the relationship between nocturnal variables and the subsequent waking electroencephalogram (EEG), in order to determine if sleepiness was related to OSAHS severity and due to sleep fragmentation or to nocturnal hypoxaemia.

In total, 12 moderate-to-severe OSAHS patients underwent a total sleep night followed by a 24-h period of sustained wakefulness where the waking EEG was measured every hour.

The results showed that alpha $(7.9-12.6 \mathrm{~Hz})$ and beta (12.7-29.2 Hz) activities were strongly related to OSAHS severity, mainly reflected by the apnoea index. Moreover, spectral power in most of the waking EEG components was significantly correlated with nocturnal hypoxaemia indices, namely alpha and beta activity when hypoxaemia becomes severe. However, no correlation was found between the waking EEG and sleep fragmentation parameters.

In conclusion, the present results suggest that the difficulty in maintaining an optimal level of alertness, reflected by a higher activity in awake alpha and beta bands (7.9-29.2 Hz) in obstructive sleep apnoea/hypopnoea syndrome, was better explained by: 1) the apnoea as opposed to the hypopnoea index; and 2) nocturnal hypoxaemia as opposed to sleep fragmentation.

KEYWORDS: Daytime sleepiness, nocturnal hypoxaemia, obstructive sleep apnoea/hypopnoea syndrome, spectral analysis, sustained wakefulness, waking electroencephalogram

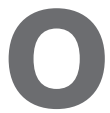

bstructive sleep apnoea/hypopnoea syndrome (OSAHS) is a common disorder, characterised by recurrent cessation of airflow during sleep that results in intermittent hypoxaemia and leads to repetitive arousals from sleep, resulting in a constant interruption of the normal sleep pattern and daytime sleepiness [1]. Nevertheless, different aspects of disturbed sleep could be responsible for sleepiness in OSAHS. The sleep apnoea/hypopnoea index (AHI), the most common clinical estimate of OSAHS severity, was considered by some studies to be the best predictor of daytime sleepiness [2, 3], whereas others did not find such a relationship $[4,5]$. This discrepancy between studies may be explained by the ambiguity of the concept of the AHI as an estimate of the OSAHS severity [6]. Since OSAHS induces multiple awakenings, as well as blood oxygen desaturation, the AHI could refer to either of these two features. Thus, in patients who awaken at each apnoea event, this index may primarily reflect sleep fragmentation, while in those who awaken less frequently but undergo more severe oxygen desaturation during apnoea events, this index may essentially reflect the nocturnal hypoxaemia. The primary aim of the present study was to examine whether apnoea severity measured by the AHI was related to daytime sleepiness measured by the waking electroencephalogram (EEG), and to which extent this was predominantly due to previous nocturnal hypoxaemia or sleep fragmentation.

\section{METHODS}

\section{Subjects and design}

In total, 12 male OSAHS patients aged 35-64 yrs (mean \pm SE $51.2 \pm 2.5 \mathrm{yrs}$ ) volunteered for the present experiment. They underwent a medical examination showing regular sleep-wake cycles, with no medical or psychiatric history (except apnoea) and were free from any medication. The selected patients were characterised by a sleep
AFFILIATIONS

*Laboratory of Imaging and Cognitive Neuroscience (LINC CNRS),

"University Louis Pasteur

"Federal Institute of Neurosciences (IFR 37),

+Sleep Disorders Unit, Civil Hospital Strasbourg, and

${ }^{\S}$ Forenap FRP, Rouffach, France.

CORRESPONDENCE

J. Grenèche

LINC (Laboratoire d'Imagerie et de Neurosciences Cognitives)

CNRS-UMR 7191

21 rue Becquerel

67087 Strasbourg

France

Fax: 33388106245

E-mail: Jerome.Greneche@linc.

u-strasbg.fr

Received:

September 052007

Accepted after revision:

April 172008

\section{SUPPORT STATEMENT}

This study received financial support from the Foundation MAIF, Niort, France.

STATEMENT OF INTEREST None declared. 


\begin{tabular}{|c|c|c|}
\hline TABLE 1 & \multicolumn{2}{|c|}{$\begin{array}{l}\text { Clinical, anthropometric, nocturnal respiratory } \\
\text { and polysomnographic findings among } \\
\text { obstructive sleep apnoea/hypopnoea syndrome } \\
\text { patients, stratified according to the American } \\
\text { Academy of Sleep Medicine criteria [8] }\end{array}$} \\
\hline Variables & & Values \\
\hline Subjects $\mathrm{n}$ & & 12 \\
\hline \multicolumn{3}{|c|}{ Sociodemographic features } \\
\hline Age yrs & & $51.2 \pm 2.5$ \\
\hline $\mathrm{BMl} \mathrm{kg} \cdot \mathrm{m}^{-2}$ & & $29.9 \pm 1.5$ \\
\hline \multicolumn{3}{|c|}{ Respiratory variables } \\
\hline AHI events. & & $66.1 \pm 11.2$ \\
\hline Al events $\cdot h$ & & $29.8 \pm 10.5$ \\
\hline $\mathrm{HI}$ events.h & & $36.3 \pm 8.5$ \\
\hline Minimal sle & $\mathrm{Sa}, \mathrm{O}_{2} \%$ & $81.9 \pm 3.2$ \\
\hline Time $^{\#}$ with & leep $\mathrm{Sa}_{1} \mathrm{O}_{2}<80 \%$ & $2.1 \pm 1.2$ \\
\hline Time $^{\#}$ with & leep $\mathrm{Sa}, \mathrm{O}_{2}<90 \%$ & $38.1 \pm 17.2$ \\
\hline $\mathrm{ODI}>4 \%$ & & $37.6 \pm 10.8$ \\
\hline \multicolumn{3}{|c|}{ Polysomnographic variables } \\
\hline TST min & & $376.4 \pm 16.2$ \\
\hline Sleep efficie & רcy \% & $77.3 \pm 2.8$ \\
\hline Stage 2 late & cy min & $18.7 \pm 7.4$ \\
\hline SWS latenc & $\min$ & $69.7 \pm 15.1$ \\
\hline REM latenc & $\min$ & $145.0 \pm 12.9$ \\
\hline Stage $1 \mathrm{sle}$ & p \% & $14.7 \pm 2.3$ \\
\hline Stage 2 sle & p \% & $44.4 \pm 3.3$ \\
\hline Stage $3-4 \varsigma$ & eep \% & $25.2 \pm 3.8$ \\
\hline REM sleep & & $15.7 \pm 2.1$ \\
\hline $\mathrm{Arl}^{+}$ & & $3.4 \pm 0.8$ \\
\hline$A \mathrm{Wl}^{+}$ & & $18.3 \pm 4.7$ \\
\hline $\mathrm{ArAwl}^{+}$ & & $22.6 \pm 3.8$ \\
\hline Sleep stage & changes index & $67.9 \pm 13.2$ \\
\hline \multicolumn{3}{|c|}{ Subjective sleepiness } \\
\hline ESS score & & $13.0 \pm 1.3$ \\
\hline
\end{tabular}

Data are presented as mean $\pm \mathrm{SE}$. BMI: body mass index; AHI: apnoea/ hypopnoea index; Al: apnoea index; $\mathrm{HI}$ : hypopnoea index; $\mathrm{Sa}_{2} \mathrm{O}_{2}$ : arterial oxygen saturation; ODI: oxygen desaturation index; TST: total sleep time; SWS: slow-wave sleep; REM: rapid eye movement; Arl: arousal index; Awl: awakening index; ArAwl: arousal/awakening index; ESS: Epworth Sleepiness Scale. \#: percentage of TST; ${ }^{\bullet}$ : SWS; ${ }^{+}$: per hour of TST

AHI $>20$ (table 1) and a minimal sleep arterial oxygen saturation $\left(\mathrm{Sa}_{1} \mathrm{O}_{2}\right)<92 \%$. The study involved one adaptation night followed 7 days later by a 32-h experimental session. It included a baseline 8-h night in a single room from 23:00 to 07:00 h, followed by a $24-\mathrm{h}$ period of sustained wakefulness. During the 24-h period of sustained wakefulness, the waking EEG was assessed every hour using a modified version of the Karolinska Drowsiness Test [7]. The patients were monitored polygraphically for 9 min while seated in a comfortable chair in a quiet single room at a distance of $2 \mathrm{~m}$ from the wall on which a $100-\mathrm{mm}$ " $X$ " made with red tape had been placed at eye level. During the recordings, they were instructed to relax, keep their eyes open for $3 \mathrm{~min}$ and focus on the red tape avoiding, as far as possible, eye blinks and movements. For the next $3 \mathrm{~min}$, they were told to close their eyes, and for the last $3 \mathrm{~min}$ to open their eyes again. Between the EEG recordings, all patients were given freedom of movement but were continuously observed by the experimental staff.

\section{Polysomnographic recordings}

The sleep EEG was recorded during the baseline night from 23:00 to $07: 00 \mathrm{~h}$ (table 1 ) and analysed through visual scoring, following the standard procedure defined by RECHTSCHAFFEN and KALES [9]. The criteria for EEG arousals were defined by the American Sleep Disorders Association [10] and respiratory events were scored according to the criteria of the American Academy of Sleep Medicine [8]. Apnoea severity was measured by the AHI (number of apnoeas/number of apnoeas plus hypopnoeas per hour of sleep), the apnoea index (AI; number of apnoeas per hour of sleep) and the hypopnoea index (HI; number of hypopnoeas per hour of sleep). The sleep fragmentation parameters included the index of arousals (ArI; number of arousals/total sleep time (TST)), the index of awakenings (AwI; number of awakenings/TST), the indices of arousals and awakenings (ArAwI; number of arousals and awakenings/TST) and the sleep stage changes index (number of sleep stage changes/TST). The arousals were defined as lasting $>3 \mathrm{~s}$ and the awakenings as lasting $\geqslant 15 \mathrm{~s}$. Indices of nocturnal hypoxaemia included the lowest $\mathrm{S}_{\mathrm{a}, \mathrm{O}_{2}}$ during sleep and the percentage of sleep with $\mathrm{Sa}_{\mathrm{a}} \mathrm{O}_{2}<90 \%$ and $<80 \%$, measured with a transcutaneous finger pulse oximeter.

\section{EEG recordings and analysis}

Four EEG derivations were recorded: F3, C3, P3 and O1 referenced to the right mastoid (A2), right and left electrooculograms from the outer canthus referenced to the left mastoid (A1), one electromyogram of the chin, and an ECG. The SCAN LT software version 1.1 (Neuroscan Medical Systems, Sterling, VA, USA) was used for data acquisition. Spectral analysis (Fast Fourier Transform) was performed on the C3-A2 derivation (showing the least movements and eyelid artefacts) using the Brain Vision Analyzer program version 1.04 (Brain Products GmbH, Munich, Germany). Body movements or eyelid artefacts were removed, as appropriate, from further analysis of the measured EEG. The absolute power values of EEG components known to be sensitive to sleepiness were computed: delta $(0.5-3.8 \mathrm{~Hz})$, theta $(3.9-7.8 \mathrm{~Hz})$, alpha $(7.9-12.6 \mathrm{~Hz})$ and beta $(12.7-29.2 \mathrm{~Hz})$ power. Care was taken to distinguish the frequency range for all adjacent EEG bands, which were computed as previously described [11].

\section{Statistical analysis}

Tests of normality and variance homogeneity were performed on each EEG frequency band, anthropometric, clinical and polysomnographic variable. Since normal distribution and variance homogeneity could not be assumed for all clinical, anthropometric, polysomnographic and respiratory variables, Spearman rank-order correlations were used in OSAHS patients to compare the 25 averaged values for each EEG frequency band and the polysomnographic and sleep-related respiratory variables.

\section{RESULTS}

\section{Respiratory and polysomnographic variables}

Table 1 summarises the clinical and anthropometric variables of the patients, as well as the nocturnal sleep and respiratory variables. 


\section{Relationships between apnoea severity, sleep fragmentation variables and the waking EEG}

As shown in table 2, the total AHI in OSAHS patients was positively correlated with awake alpha power $(\mathrm{r}=0.66, \mathrm{p}<0.05)$. Moreover, AI was positively correlated with the alpha $(r=0.62$, $\mathrm{p}<0.05)$ and beta $(\mathrm{r}=0.57, \mathrm{p}<0.05)$ powers, while no correlation was found between $\mathrm{HI}$ and any of the waking EEG components. No significant correlation was found between sleep fragmentation parameters, whatever the selected index, and the waking EEG component.

\section{Relationship between nocturnal hypoxaemia and the waking EEG}

The oxygen desaturation index was positively correlated with theta $(\mathrm{r}=0.88, \mathrm{p}<0.01)$ and alpha powers $(\mathrm{r}=0.68, \mathrm{p}<0.05)$. The minimum $\mathrm{Sa}_{1} \mathrm{O}_{2}$ during sleep was negatively correlated with awake beta power $(\mathrm{r}=-0.83, \mathrm{p}<0.01)$, while the time spent with $\mathrm{Sa}_{1} \mathrm{O}_{2}<90 \%$ was positively correlated with most of the waking EEG measures (beta: $\mathrm{r}=0.77, \mathrm{p}<0.01$; alpha: $\mathrm{r}=0.73$, $\mathrm{p}<0.05$; theta: $\mathrm{r}=0.66, \mathrm{p}<0.05)$. The most severe hypoxaemic measure, i.e. the time spent with $\mathrm{Sa}_{1} \mathrm{O}_{2}<80 \%$, was positively correlated with the alpha power $(\mathrm{r}=0.70, \mathrm{p}<0.05)$.

\section{Relationships between nocturnal variables and the Epworth score}

As shown in table 3, no significant correlation was found between nocturnal parameters and the mean Epworth Sleepiness Scale (ESS) score in OSAHS patients.

\section{DISCUSSION}

The present study showed that daytime sleepiness, measured by various components of the waking EEG [12, 13], may be related to apnoea severity as suggested by the relationship between $\mathrm{AHI}$ and the increase in the waking alpha power. Moreover, this correlation was mainly due to the AI, as shown

\begin{tabular}{|c|c|c|c|c|c|}
\hline \multicolumn{2}{|c|}{ Waking EEG variables } & Delta & Theta & Alpha & Beta \\
\hline \multicolumn{6}{|c|}{ Respiratory variables } \\
\hline $\mathrm{AHI}$ & & 0.32 & 0.45 & $0.66^{\star}$ & 0.24 \\
\hline Al & & 0.44 & 0.22 & $0.62^{*}$ & $0.57^{\star}$ \\
\hline $\mathrm{HI}$ & & -0.19 & 0.13 & 0.05 & -0.46 \\
\hline $\mathrm{ODI}>4 \%$ & & 0.35 & $0.88^{* *}$ & $0.68^{*}$ & -0.04 \\
\hline Minimal slee & $\mathrm{p} \mathrm{Sa}, \mathrm{O}_{2}$ & -0.46 & -0.35 & -0.51 & $-0.83^{\star \star}$ \\
\hline Time with sle & $\mathrm{ep} \mathrm{Sa}_{1} \mathrm{O}_{2}<80 \%$ & 0.23 & 0.42 & $0.70^{\star}$ & 0.52 \\
\hline Time with sle & $\mathrm{ep} \mathrm{S}_{1} \mathrm{O}_{2}<90 \%$ & 0.47 & $0.66^{\star}$ & $0.73^{\star}$ & $0.77^{\star \star}$ \\
\hline \multicolumn{6}{|c|}{ Polysomnographic variables } \\
\hline Awl & & 0.40 & 0.54 & 0.52 & 0.39 \\
\hline Arl & & -0.10 & -0.21 & 0.05 & 0.20 \\
\hline Sleep stage & changes index & -0.07 & 0.33 & 0.25 & 0.23 \\
\hline
\end{tabular}

Data are presented as Spearman coefficient $r$ (rho) values. AHI: apnoea/ hypopnoea index; Al: apnoea index; HI: hypopnoea index; ODI: oxygen desaturation index; $\mathrm{Sa}_{1} \mathrm{O}_{2}$ : arterial oxygen saturation; Awl: awakening index; Arl: arousal index. ${ }^{*}: \mathrm{p}<0.05 ;{ }^{* *}: \mathrm{p}<0.01$

\begin{tabular}{|c|c|c|}
\hline TABLE 3 & \multicolumn{2}{|c|}{$\begin{array}{l}\text { Nonparametric regression showing relationships } \\
\text { between the Epworth Sleepiness Scale (ESS) } \\
\text { score and nocturnal variables in obstructive } \\
\text { sleep apnoea/hypopnoea syndrome patients }\end{array}$} \\
\hline Subjective sl & epiness variables & ESS score \\
\hline \multicolumn{3}{|c|}{ Respiratory variables } \\
\hline $\mathrm{AHI}$ & & -0.20 \\
\hline AHI non-RE & & -0.18 \\
\hline AHI REM & & 0.09 \\
\hline $\mathrm{Al}$ & & -0.07 \\
\hline $\mathrm{HI}$ & & -0.15 \\
\hline $\mathrm{ODI}>4 \%$ & & -0.11 \\
\hline Minimal sle & $\mathrm{Sa}, \mathrm{O}_{2}$ & -0.35 \\
\hline Time with $\mathrm{s}$ & ep $\mathrm{Sa}, \mathrm{O}_{2}<80 \%$ & -0.18 \\
\hline Time with s & ep $\mathrm{Sa}_{1} \mathrm{O}_{2}<90 \%$ & 0.20 \\
\hline \multicolumn{3}{|c|}{ Polysomnographic variables } \\
\hline Awl & & 0.15 \\
\hline Arl & & -0.46 \\
\hline Sleep stage & changes index & 0.20 \\
\hline
\end{tabular}

Data are presented as Spearman coefficient $r$ (rho) values. AHI: apnoea/ hypopnoea index; REM: rapid eye movement; Al: apnoea index; HI: hypopnoea index; ODI: oxygen desaturation index; $\mathrm{Sa}_{2} \mathrm{O}_{2}$ : arterial oxygen saturation; Awl: awakening index; Arl: arousal index.

previously by CHERVIN and ALDRICH [14], who found a more pronounced effect of apnoea (compared with hypopnoea) on daytime sleepiness. The current results also suggest that the AI could be related to the efforts to stay awake, reflected by an increase in beta power [15] that is supposed to counteract the sleep pressure. However, the difficulties in finding correlations between the AHI and the low frequency range activity (0.5$7.8 \mathrm{~Hz}$ ) may be due to a complex interaction between nocturnal hypoxaemia and sleep fragmentation. Therefore, the present study focused on the respective contribution of these two factors on daytime sleepiness. In this respect, it appears that daytime sleepiness is predominantly related to nocturnal hypoxaemia, rather than sleep fragmentation. However, subjective sleepiness rated with the ESS score in OSAHS patients was never related to sleep and respiratory disturbances, most probably because the ESS is defined as a "trait" assessment of recent dozing behaviour but does not necessarily represent the subjective sleepiness truly exhibited during the experimental session.

Studies conducted in OSAHS patients [12] and in non-sleepdeprived subjects [16, 17] have previously shown that hypoxaemia was associated with waking EEG changes and alertness impairment. The results of the current study show higher activity in most of the waking EEG markers as a function of the time spent with $\mathrm{Sa}_{\mathrm{a}_{1}} \mathrm{O}_{2}<90 \%$. It was also found that awake alpha $(7.9-12.6 \mathrm{~Hz})$ and beta $(12.7-29.2 \mathrm{~Hz})$ activities were correlated with lower $\mathrm{Sa}_{\mathrm{O}_{2}} \mathrm{O}_{2}$ and time spent with $\mathrm{Sa}_{1} \mathrm{O}_{2}<80 \%$. Additionally, the oxygen desaturation index during sleep was correlated with higher activity in awake theta $(3.9-7.8 \mathrm{~Hz})$ and alpha $(7.9-12.6 \mathrm{~Hz})$ bands. In line with BENNETT et al. [18], this finding suggests that the index of respiratory disturbances may play a primary role in the degree 
of sleepiness. In contrast, in the present study, sleep fragmentation measures were not related to the waking EEG changes, although apnoea-related sleep fragmentation has been shown to play a role in sleep propensity [19-21]. Therefore, in agreement with previous reports [6, 22-24], the current results suggest that the severity of nocturnal hypoxaemia, as opposed to sleep fragmentation, could be the primary determinant of impaired alertness, especially in severe OSAHS patients who exhibit numerous and deep sleep oxygen desaturation events. However, the role of arousals and awakenings should not be underestimated, since not all apnoeas and hypopnoeas are terminated by visible cortical arousals or awakenings [25,26] and, according to REES et al. [27], this could be the case for $\sim 30 \%$ of them. Fragmented sleep was assessed with only some parameters, whereas other measures of sleep fragmentation may better correlate with EEG spectral parameters, especially autonomic measures using cardiac activation during arousal [28]. Moreover, sleep propensity and efforts to remain awake probably represent distinct physiological processes [29] and, therefore, the cause of sleepiness in OSAHS may be multifactorial, as suggested by Chervin and Aldrich [14] and POCETA et al. [23]. Finally, the present study was conducted on a small sample size of 12 moderate-to-severe OSAHS patients. This was due to the fact that five patients with EEG artefact removal $>30 \%$ were excluded from further analysis. Therefore, the present data need to be confirmed by further studies conducted on larger groups. Nevertheless, it should be emphasised that this extensive study was conducted over $24 \mathrm{~h}$ of sustained wakefulness with hourly EEG tests, in order to optimise the analysis of the waking EEG time-course over acute sleep deprivation in OSAHS patients.

Further investigations should, therefore, be conducted within two groups clearly differing in the degree of obstructive sleep apnoea/hypopnoea syndrome severity, in order to examine more accurately the involvement of nocturnal hypoxaemia and sleep fragmentation in the occurrence of daytime sleepiness.

\section{ACKNOWLEDGEMENTS}

The authors would like to thank the staff of the Sleep Disorders Unit of the Civil Hospital of Strasbourg (France), especially B. Kowalski, C. Mansouri and C. Sellal for scoring the sleep stages. They would also like to express especial thanks to all the subjects who participated in the study.

\section{REFERENCES}

1 Guilleminault C. Clinical features and evaluation of obstructive sleep apnea. In: Kryger MH, Roth T, Dement WC, eds. Principles and Practice of Sleep Medicine, Philadelphia, Saunders, 1989; pp. 552-558.

2 Roth T, Hartse KM, Zorick F, Conway W. Multiple naps and the evaluation of daytime sleepiness in patients with upper airway sleep apnea. Sleep 1980; 3: 425-439.

3 Timms RM, Khaja FU, Williams GW. Hemodynamic response to oxygen therapy in chronic obstructive pulmonary disease. Ann Intern Med 1985; 102: 29-36.

4 Guilleminault C, Partinen M, Quera-Salva MA, Hayes B, Dement WC, Nino-Murcia G. Determinants of daytime sleepiness in obstructive sleep apnea. Chest 1988; 94: 32-37.
5 Kingshott RN, Englemann HM, Deary IJ, Douglas NJ. Does arousal frequency predict daytime function? Eur Respir J 1998; 12: 1264-1270.

6 Bédard MA, Montplaisir J, Richer F, Rouleau I, Malo J. Obstructive sleep apnea syndrome: pathogenesis of neuropsychological deficits. J Clin Exp Neuropsychol 1991; 13: 950-964.

7 Akerstedt T, Gillberg M. Subjective and objective sleepiness in the active individual. Intern J Neuroscience 1990; 52 : 29-37.

8 Sleep-related breathing disorders in adults: recommendations for syndrome definition and measurement techniques in clinical research. The Report of an American Academy of Sleep Medicine Task Force. Sleep 1999; 22: 667-689.

9 Rechtschaffen A, Kales A, eds, A Manual of Standardized Terminology, Techniques, and Scoring System for Sleep Stages in Human Subjects. Washington DC, US National Public Health Service, US Government Printing Office, 1968.

10 EEG arousals: scoring rules and examples: a preliminary report from the Sleep Disorders Atlas Task Force of the American Sleep Disorders Association. Sleep 1992; 15: 173-184.

11 Grenèche J, Krieger J, Erhardt C, et al. EEG spectral power and sleepiness during $24 \mathrm{~h}$ of sustained wakefulness in patients with obstructive sleep apnea syndrome. Clin Neurophysiol 2008; 119: 418-428.

12 Morisson F, Lavigne G, Petit D, Nielsen T, Malo J, Montplaisir J. Spectral analysis of wakefulness and REM sleep EEG in patients with sleep apnoea syndrome. Eur Respir J 1998; 11: 1135-1140.

13 Sforza E, Grandin S, Jouny C, Rochat T, Ibanez V. Is waking electroencephalographic activity a predictor of daytime sleepiness in sleep-related breathing disorders? Eur Respir J 2002; 19: 645-652.

14 Chervin RD, Aldrich MS. Characteristics of apneas and hypopneas during sleep and relation to excessive daytime sleepiness. Sleep 1998; 21: 799-806.

15 Lorenzo I, Ramos J, Arce C, Guevara MA, Corsi-Cabrera M. Effect of total sleep deprivation on reaction time and waking EEG activity in man. Sleep 1995; 18: 346-354.

16 Kraaier V, Van Huffelen AC, Wieneke GH. Quantitative EEG changes due to hypobaric hypoxia in normal subjects. Electroencephalogr Clin Neurophysiol 1988; 69: 303-312.

17 Saletu B, Grünberger J, Anderer P, Linzmayer L, König P. On the cerebro-protective effects of caroverine, a calciumchannel blocker and antiglutamatergic drug: double-blind, placebo-controlled, EEG mapping and psychometric studies under hypoxia. Br J Clin Pharmacol 1996; 41: 89-99.

18 Bennett LS, Langford BA, Stradling JR, Davies RJO. Sleep fragmentation indices as predictors of daytime sleepiness and nCPAP response in obstructive sleep apnea. Am J Respir Crit Care Med 1998; 158: 778-786.

19 Chugh DK, Weaver TE, Dinges DF. Neurobehavioral consequences of arousals. Sleep 1996; 19: Suppl. 10, S198-S201.

20 Roehrs T, Zorick F, Wittig R, Conway W, Roth T. Predictors of objective level of daytime sleepiness in patients with sleep-related breathing disorders. Chest 1989; 95: 1202-1206.

21 Martin SE, Engleman HM, Deary IJ, Douglas NJ. The effect of sleep fragmentation on daytime function. Am J Respir Crit Care Med 1996; 153: 1328-1332.

22 Punjabi NM, O'Hearn DJ, Neubauer DN, et al. Modeling hypersomnolence in sleep-disordered breathing. A novel 
approach using survival analysis. Am J Respir Crit Care Med 1999; 159: 1703-1709.

23 Poceta JS, Timms RM, Jeong DU, Ho SL, Erman MK, Mitler MM. Maintenance of wakefulness test in obstructive sleep apnea syndrome. Chest 1992; 101: 893-897.

24 Montplaisir J, Bédard MA, Richer F, Rouleau I. Neurobehavioral manifestations in obstructive sleep apnea syndrome before and after treatment with continuous positive airway pressure. Sleep 1992; 15: Suppl. 6, S17-S19.

25 Martin SE, Wraith PK, Deary IJ, Douglas NJ. The effect of nonvisible sleep fragmentation on daytime function. Am J Respir Crit Care Med 1997; 155: 1596-1601.
26 Martin SE, Engleman HM, Kingshott RN, Douglas NJ. Microarousals in patients with sleep apnoea/hypopnoea syndrome. J Sleep Res 1997; 6: 276-280.

27 Rees K, Spence DP, Earis JE, Calverley PM. Arousal responses from apneic events during non-rapid-eye-movement sleep. Am J Respir Crit Care Med 1995; 152: 1016-1021.

28 Sforza E, Jouny C, Ibanez V. Cardiac activation during arousal in humans: further evidence for hierarchy in the arousal response. Clin Neurophysiol 2000; 111: 1611-1619.

29 Sangal RB, Thomas L, Mitler MM. Disorders of excessive sleepiness. Treatment improves ability to stay awake but does not reduce sleepiness. Chest 1992; 102: 699-703. 